6. Kirakli C, Ozdemir I, Ucar ZZ, Cimen P, Kepil S, Ozkan SA. Adaptive support ventilation for faster weaning in COPD: a randomised controlled trial. Eur Respir J. 2011;38(4):774-780. doi:10.1183/09031936.00081510
7. Mohamed KAE, kamal EI Maraghi S. Role of adaptive support ventilation in weaning of COPD patients. Egypt J Chest Dis Tuberc. 2014;63(2):449-454.

\title{
ĐẶC ĐIỂM LÂM SÀNG RỐI LOẠN CHỨC NĂNG TÌNH DỤC Ở NAM BÊNNH NHÂN ĐÁI THÁO ĐƯỜNG TYPE 2 TẠI BÊ̂NH VIỆN BẠCH MAI
}

\section{TÓM TẮT}

Đặt vấn đê: Rối loạn chức năng tình dục là một rối loạn thường gặp ở bệnh nhân đái tháo đường type 2. Rổi loạn chức năng tình dục làm suy giảm chất lượng cuộc sống, đăt ra môt thách thức đối với mối quan hệ vợ chồng, ảnh hưởng tới quá trình tuân thủ điều tri của bênh nhân. Mục tiêu nghiên cứu: Mô tả đăc điểm lâm sàng rối loạn chức năng tình dục ở nam bểnh nhân đái tháo đường type 2 . Đối tượng và phương pháp nghiên cứu: Nghiên cứu mổ tả cắt ngang 165 nam bệnh nhân đái tháo đường type 2 điêu trị tại phòng khám Nội tiết - Đái Tháo Đường Khoa khám bệnh - Bệnh viện Bạch Mai từ tháng 08/2020 đến tháng 08/2021. Kết quả: Đối tượng nghiên cứu có độ tuổi trung bình $63,47 \pm 10,14$; nới sinh sống chủ yếu ở thành thị 73,9\%; trình độ học vân cao đẳng, đại học và sau đại học $37,6 \%$, thời gian mắc đái tháo đường trung bình là $8,66 \pm 4,95$ năm, $68,5 \%$ bệnh nhân có rối loạn cương dương, thời gian trung bình có rối loan cương dương là 3,18 $\pm 1,04$ sau khi mắc đái tháo dường; $34,5 \%$ bệnh nhân đánh giá trên thang chất lượng cuộc sống là hòa lấn giữa thỏa mãn và bất mãn. Kết luận: Rối loan chức năng tình dục là một rối loạn thường gặp ở bệnh nhân đái tháo đường type 2 và làm giảm chất lượing cuộc sống của bệnh nhân.

Tư khoá: Đái tháo đường type 2, Rối loạn chức năng tình dục, Đặc điểm lâm sàng.

\section{SUMMARY}

CLINICAL FEATURES OF SEXUAL DYSFUNCTION AMONG MALE PATIENTS WITH TYPE 2 DIABETES IN BACH MAI HOSPITAL

Background: Sexual dysfunction (SD) is one of the common disorders in patients with diabetes. SD affects many aspects such as reducing quality of life, interference with sexual life, problems with partners, increase in stress and poor glycemic control. Objectives: To describe clinical features of Sexual

\footnotetext{
${ }^{1}$ Đai hoc Y Hà Nôi

2Viện sức khỏe Tâm thần, Bênhh viện Bạch Mai Chịu trách nhiệm chính: Nguyễn Thị Phương Email: nguyenphuongpupa@gmail.com Ngày nhận bài: 28.7.2021

Ngày phản biện khoa học: 28.9.2021

Ngày duyệt bài: 5.10 .2021
}

dysfunction in male patients with type 2 diabetes. Subjects and research methods: A cross-sectional descriptive study of 165 patients who were treated at Outpatient Department of Diabetes and Endocrinology, Bach Mai Hospital from August 2020 to August 2021. Results: The study subjects sociademographic characteristics: average age - 63,47 $\pm 10,14$; living in urban areas $-73,9 \%$, The average period of time in which the patients were facing diabetes was 8,66 \pm 4,95 years, Erectile dysfunction was also evident in $68,5 \%$ patients, The mean time of having erectile dysfunction after diabetes was $3.18 \pm 1.04$ years; $34,5 \%$ patients evaluate mixed about equally satisfied and dissatisfied in QoL Score. Conclusion: Sexual dysfunction is extremely common among type 2 diabetic patients and is associated with poorer quality of life.

Keywords: Type 2 Diabetes, Sexual dysfunction, Clinical features.

\section{I. ĐẶT VẤN ĐỀ}

Bê̂nh đái tháo đường (ĐTĐ) là một bệnh chuyển hóa man tính, đặc trưng bởi nồng độ glucose trong máu tăng cao, dẫn đến tổn thương nghiêm trọng đến tim, mạch máu, mắt, thận và thân kinh. Liên đoàn Đái tháo đường thế giới chỉ ra, bệnh ĐTĐ hiện nay có thể coi là một loại bệnh dịch toàn cầu với 415 triệu người trưởng thành bi bênh trên toàn thế giới mắc bênh đái tháo đường, chiếm ( $8,8 \%$ dân số thế giới). Tại Việt Nam, số liệu từ Hội Nội tiết và ĐTĐ (VADE) cho biết, hiện có tới 3,53 triệu người đang "chung sống" với căn bệnh ĐTĐ, và mỗi ngày có ít nhất 80 trường hợp tử vong vì các biến chứng liên quan. Dự báo, số người bắc bệnh có thể tăng lên 6,3 triệu vào năm 2045².

Bệnh ĐTĐ có liên quan đến rối loạn chức năng tình dục (RLCNTD) ở cả nam và nữ. ĐTĐ làm tăng gấp ba lân nguy cơ rối loạn cương dương ở bệnh nhân ĐTĐ so với nam giới không mắc bệnh². Ngoài ra, RLCNTD đặt ra một thách thức đối với mối quan hệ vợ chồng, nó dẫn đến ít sự hài lòng trong hôn nhân, căng thẳng, hạn chế giao tiếp và gây khó khăn trong giải quyết vấn đề, và có thể dẫn đến ly hôn ${ }^{3}$. Hơn nữa, khả năng tự chăm sóc bản thân giảm khi có mâu 
thuẫn trong các mối quan hệ hôn nhân sẽ kéo theo sự kiểm soát đường huyết kém ${ }^{4}$.

Hiện nay, tại Việt Nam đã có nhiều đề tài nghiên cứu về những khía cạnh khác nhau của ĐTÐ, nhưng chưa có đề tài nghiên cứu về đặc điểm lâm sàng RLCNTD ở bệnh nhân ĐTĐ mà chỉ dùng các thang đánh giá. Với tầm quan trọng và thực trạng hiện nay, để nâng cao chất lượng cuộc sống của bệnh nhân đồng thời góp phần nâng cao hiệu quả điều trị bệnh, tôi xin thực hiên nghiên cứu với đề tài: "Nghiên cứu đặc điểm lâm sàng rối loạn chức năng tình dục ở nam bệnh nhân đái tháo đường type 2 tại bệnh viên Bạch Mai" với muc tiêu "Mô tả đăc điểm lâm sàng rối loạn chức năng tình dục ở nam bênh nhân đái tháo đường type 2 tại bệnh viện Bạch Mai từ tháng 8/2020 đến tháng 8/2021"

\section{II. ĐỐI TƯƠ'NG VÀ PHƯƠNG PHÁP NGHIÊN CỨU}

2.1. Đối tượng nghiên cứu: 165 nam bệnh nhân ĐTĐ type 2 điêuu trị tại phòng khám Nội tiết - Đái tháo đường - Khoa khám bệnh - Bệnh viện Bạch Mai từ tháng 08/2020 đến tháng 08/2021.

2.2. Tiêu chuẩn lựa chọn: Tất cả nam bệnh nhân được các bác sỹ chuyên khoa Nội Tiết chẩn đoán là mắc ĐTĐ type 2 đồng ý tham gia nghiên cứu.

2.3. Tiêu chuẩn loại trừ: Bệnh nhân mắc các bệnh cơ thể nặng hoặc mắc các RLCNTD trước khi mắc ĐTÐ type 2

2.4. Phương pháp nghiên cứu: Phương pháp mô tả cắt ngang, cỡ mẫu thuận tiện. Số liệu được xử lý bằng phần mềm SPSS 20.0.

2.5. Đạo đức nghiên cứu: Số liệu được mã hoá nhằm giữ bí mật thông tin cho người bệnh. Đây là nghiên cứu mô tả không can thiệp chẩn đoán và điêu trị, không ảnh hưởng đến sức khỏe bệnh nhân. Bệnh nhân đồng ý tham gia nghiên cứu.

\section{KẾT QUẢ VÀ BÀN LUÂN}

3.1. Đặc điểm chung của nhóm nghiên cứu

Bảng 1. Đặc điểm chung của nhóm đối tượng nghiên cứu ( $N=165)$

\begin{tabular}{|c|c|c|c|}
\hline \multicolumn{2}{|c|}{ Đăc điếm chung } & Số BN & $\%$ \\
\hline & Lối trung bình & \multicolumn{2}{|c|}{$63,47 \pm 10,14$} \\
\hline \multirow{3}{*}{ Nơi ở } & Nông thôn & 43 & 26,1 \\
\hline & Thành thi & 122 & 73,9 \\
\hline & Miền núi & 0 & 0,0 \\
\hline \multirow{4}{*}{$\begin{array}{l}\text { Trình độ } \\
\text { học vấn }\end{array}$} & Tiểu học & 16 & 9,7 \\
\hline & Trung học cơ sở & 36 & 21,8 \\
\hline & Trung học phố thông & 51 & 30,9 \\
\hline & CĐ-ĐH và SĐH & 62 & 37,6 \\
\hline \multirow{2}{*}{$\begin{array}{c}\text { Nghề } \\
\text { nghiệp }\end{array}$} & Nông dân & 21 & 12,7 \\
\hline & Công nhân & 8 & 4,8 \\
\hline
\end{tabular}

\begin{tabular}{|c|c|c|c|}
\hline \multirow{4}{*}{} & Viên chức & 15 & 9,1 \\
\cline { 2 - 4 } & Hưu trí & 77 & 46,7 \\
\cline { 2 - 4 } & Kinh doanh & 15 & 9,1 \\
\cline { 2 - 4 } & Tự do & 29 & 17,6 \\
\hline Thời gian mắc ĐTĐ trung bình \\
(năm)
\end{tabular}

Nhận xét: Nghiên cứu của chúng tôi đã thu thập được 165 đối tượng nghiên cứu, độ tuổi trung bình là $63,47 \pm 10,14$. Kết quả này tương đồng với nghiên cứu của Mette $B$. Pedersen và CS với tuổi trung bình của nhóm nghiên cứu là $64,9 \pm 6,9^{5}$

Nghề nghiệp phổ biến nhất là hưu trí (46,7\%), các đối tượng nghiên cứu chủ yếu sống ở thành thị $(73,9 \%)$, trình độ học vấn được báo cáo nhiêu nhất là $\mathrm{CĐ}-\bigoplus \mathrm{H}$ và $\mathrm{S} \oplus \mathrm{H}(37,6 \%)$. Thời gian mắc ĐTÐ trung bình của nhóm nghiên cứu là $8,66 \pm 4,95$ năm.

3.2. Đặc điểm lâm sàng rối loạn chức năng tình dục ở nam bệnh nhân đái tháo đường type 2

3.2.1. Đặc điểm tân suât quan hệ tình dục trong 1 tuần

Bảng 2. Đăc điểm tần suât quan hê tình dục trong 1 tuần $(N=165)$

\begin{tabular}{|c|c|c|}
\hline $\begin{array}{c}\text { Số lần quan hệ tình } \\
\text { dục/tuân }\end{array}$ & $\begin{array}{c}\text { Trước khi } \\
\text { mắc ĐTÐ }\end{array}$ & Hiện tại \\
\hline Số năm mắc ĐTÐ & $3,33 \pm 0,90$ & $2,07 \pm 1,00$ \\
\hline$\leq 5$ & $3,32 \pm 1,04$ & $1,10 \pm 0,66$ \\
\hline $6-10$ & $3,16 \pm 0,69$ & $0,71 \pm 0,95$ \\
\hline$>10$ &
\end{tabular}

Nhận xét: Tần suất quan hệ tình dục trong 1 tuần của nhóm nghiên cứu trước khi mắc đái tháo đường gần như tương đồng với nhau ở nhóm mắc ĐTÐ $\leq 5$ năm, từ $6-10$ năm và $>10$ năm lần lượt là $3,33 \pm 0,90,3,32 \pm 1,04$ và 3,16 $\pm 0,69$ năm; Tần suất quan hệ tình dục trong 1 tuần giảm dần theo thời gian mắc ĐTĐ, ở nhóm mắc dưới 5 năm là $2.07 \pm 1,00$ và $0,71 \pm 0,95$ lần/ tuần ở nhóm mắc trên 10 năm.

Vì thời gian mắc ĐTĐ có liên quan đến sự gia tăng tình trạng tình trạng tổn thương mạch máu thần kinh và khả xuất hiện các biến chứng với tình trạng tổn thương mạch máu thần kinh cũng như tăng mắc đồng diễn các bệnh mạn tính khác.

3.2.2. Đăc điêm thời gian bắt đâu thay đổi chức năng tình dục sau măc đái tháo đường

Bảng 3. Thời gian bắt đầu thay đổi chức năng tình dục sau mắc $\oplus T \bigoplus$

\begin{tabular}{|c|c|}
\hline Đặc điểm & $\begin{array}{c}\text { Số năm trung } \\
\text { bình }(X \pm S D)\end{array}$ \\
\hline Rối loạn cương dương & $3,18 \pm 1,04$ \\
\hline Độ thỏa mãn khi giao hợp & $3,39 \pm 0,92$ \\
\hline
\end{tabular}




\begin{tabular}{|c|c|}
\hline Độ cực khoái & $3,51 \pm 0,94$ \\
\hline Ham muốn tình dục & $3,32 \pm 0,88$ \\
\hline Thỏa mãn toàn diện & $3,57 \pm 0,96$ \\
\hline
\end{tabular}

Nhân xét: Thời gian bắt đầu thay đổi về rối loạn cương dương là sớm nhất trong các loại RLCNTD với 3,18 $\pm 1,04$ năm sau khi mắc ĐTĐ, tiếp theo là thay đổi về ham muốn tình dục với $3,32 \pm 0,88$ năm và muộn nhất là thay đổi về thỏa mãn toàn diện với $3,57 \pm 0,96$ năm. Có nghiên cứu thấy rằng sự xuất hiện của rối loạn cương dương ở đàn ông mắc bệnh ĐTĐ sớm hởn 10-15 năm so với đàn ông không mắc ĐTĐ, thêm vào đó rối loạn cương dương ít đáp ứng với thuốc uống 7, dẫn đến giảm chất lượng cuộc sống.

3.2.3. Đặc điểm rôi loạn chức năng tình dục chung của nhóm nghiên cứu

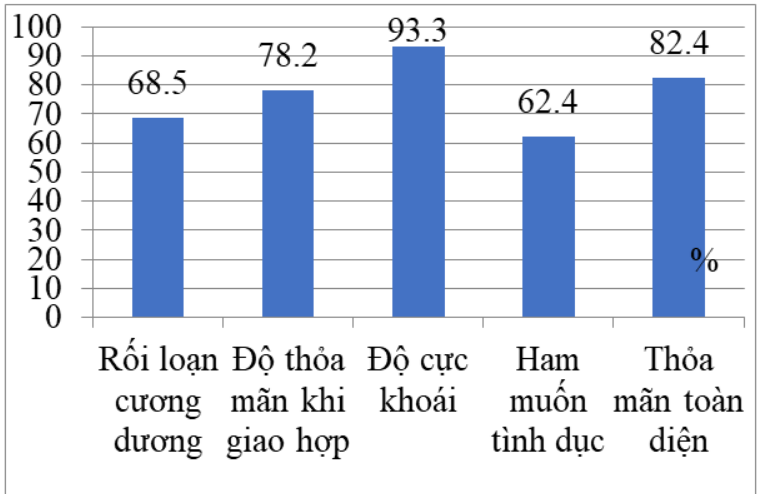

Biểu đồ 1. Đăc điểm RLCNTD chung

Nhận xét: Tỷ lệ các RLCNTD ở nhóm nghiên cứu là khá cao trong đó có $62,4 \%$ bệnh nhân có rối loạn ham muốn tình dục, tiếp theo là rối loạn cương dương (RLCD) với 68,5\% gần tương đương với NC của N H Cho và CS có tỷ lệ RLCD là $65,4 \%{ }^{6}$. Tuổi cao và thời gian mắc bệnh ĐTÐ dài hơn có liên quan đến việc tăng nguy cơ RLCD ở bệnh nhân ĐTĐ. Loại RLCNTD chiếm tỷ lệ cao nhất là rối loạn độ cực khoái với 93,3\%.

3.2.4. Đặc điểm về chất lượng cuộc sống của nhóm nghiên cứu

Bảng 4. Đặc điểm về thang đánh giá chất lượng cuộc sống theo thang QoL

\begin{tabular}{|c|c|c|}
\hline Đặc điểm & Số BN & Tý lệ \% \\
\hline Vui vẻ & 8 & 4,8 \\
\hline Hài lòng & 37 & 22,4 \\
\hline Hầu như thỏa mãn & 42 & 25,5 \\
\hline $\begin{array}{c}\text { Hòa lân giữa thóa mãn } \\
\text { và bất mãn }\end{array}$ & 57 & 34,5 \\
\hline Hầu như bất mãn & 19 & 11,5 \\
\hline Không hạnh phúc & 2 & 1,2 \\
\hline Khủng khiếp & 0 & 0,0 \\
\hline Tống & 165 & 100 \\
\hline
\end{tabular}

Nhận xét: RLCNTD ảnh hưởng tới chất lượng cuộc sống của bệnh nhân, trong đố chiếm đa số là hòa lẫn giữa thỏa mãn và bất mãn với $34,5 \%$, hầu như thỏa mãn với $11,5 \%$ và không có bệnh nhân nào cảm thấy khủng khiếp nếu quãng đời còn lại phải sống với tình trạng RLCNTD hiện tại. Mối liên hệ chặt chẽ giữa RLCNTD và suy giảm QoL chứng minh sự công nhận RLCNTD ở bệnh nhân ĐTĐ là một vấn đề sức khỏe quan trọng và kêu gọi sự quan tâm nhiều hơn đến việc xác định bệnh nhân có RLCNTD.

\section{KẾT LUẬN}

Rối loạn chức năng tình dục xuất hiện với tỉ lệ tương đối cao ở những bệnh nhân đái tháo đường với 68,5\% bệnh nhân có rối loạn cương dương, 93,3\% bệnh nhân có rối loạn độ cực khoái và ảnh hưởng đáng kể tới chất lượng cuộc sống của bệnh nhân, những bệnh nhân đái tháo đường nên được sàng lọc các rối loạn chức năng tình dục để có biện pháp quản lý kịp thời và hiệu quả, tránh diễn biến nặng nhằm nâng cao chất lượng cuộc sống cho bệnh nhân.

\section{TÀI LIỆU THAM KHẢO}

1. Thổng tin $y$ tế trên các báo ngay 12/10/2020 - tin tức sự kiện - cổng thông tin điện tứ sở y tế hà nội. accessed september 23, 2021. https://soyte.hanoi.gov.vn/tin-tuc-su-kien//asset_publisher/4ivkx5jltnbg/content/thong-tin-yte-tren-cac-bao-ngay-12-10-2020

2. Bancroft j. sexuality of diabetic women. clin endocrinol metab. 1982;11(3):785-789. doi:10.1016/s0300-595x(82)80013-3

3. Berg-cross: couples therapy: a cornerstone approach - google scholar. accessed june 23, 2020.https://scholar.google.com/scholar_lookup?tit le $=$ couples $\% 20$ therapy\&pages $=357 \quad 362 \&$ publication_year $=2001 \&$ author $=$ berg-cross $\% 2 \mathrm{cl}$

4. Klausner: perceived familial criticism and glucose... - google scholar. accessed june 23, 2020.

5. Pedersen mb, giraldi a, kristensen e, lauritzen $\mathbf{t}$, sandbæk $\mathbf{a}$, charles $\mathbf{m}$. prevalence of sexual desire and satisfaction among patients with screen-detected diabetes and impact of intensive multifactorial treatment: results from the addition-denmark study. scand $j$ prim health care. 2015;33(1):3-10. doi:10.3109/02813432.2014.1002295

6. Cho nh, ahn cw, park jy, et al. prevalence of erectile dysfunction in korean men with type 2 diabetes mellitus. diabet med $j$ br diabet assoc. 2006; 23(2):198-203. doi:10.1111/j.1464-5491.2005.01789.x

7. Do impotent men with diabetes have more severe erectile dysfunction and worse quality of life than the general population of impotent patients? | diabetes care. accessed july 23, 2020. https:// care.diabetesjournals.org/content/26/4/1093.short. 